\title{
O Centro de Educação Física e Desportos na atribuição de sentidos junto à Educação Física Escolar (1970-2004)
}

\author{
Physical Education and Sports Center in the attribution of senses to School Physical Education
} (1970-2004)

El Centro de Educación Física e Deportes en la atribución de sentidos junto a la Educación Física Escolar (1970-2004)

Juliano de Melo da Rosa ${ }^{\mathrm{I}}$, Antonio Guilherme Schmitz Filho ${ }^{\mathrm{II}}$, Jorge Luiz da Cunha ${ }^{\mathrm{III}}$, Ericsen Quincozes da Silva ${ }^{\text {IV }}$

\section{Resumo}

Este artigo resulta de uma pesquisa de natureza histórica a respeito do Centro de Educação Física e Desportos (CEFD) da UFSM. O objetivo do estudo consistiu em compreender os sentidos atribuídos pela Instituição à Educação Física Escolar, entre 1970 e 2004. Para tanto, a construção metodológica envolveu o entrecruzamento de três abordagens: entrevistas de História Oral Temática, revisão bibliográfica e revisão documental a respeito da formação profissional promovida pelo CEFD. As informações obtidas nesse processo permitiram identificar a predominância de perspectivas técnico-instrumentais e esportivas nas concepções institucionais sobre o que deveria ser desenvolvido na Educação Física Escolar, no período.

Palavras-chave: Educação Física Escolar; Tendências da Educação Física; História do CEFD/UFSM

\begin{abstract}
This article originates from a historical research that considers the Physical Education and Sports Center (PESC) of Federal University of Santa Maria (UFSM), in Brazil. The study aimed at understanding the senses attributed to School Physical Education by the Institution from 1970 to 2004. To do so, the methodological arrangement intersected three approaches: Thematic Oral History interviews, literature review and documental review about the professional qualification promoted by PESC. The information obtained in this process allowed to identify the predominance of technical-instrumental and sporty perspectives in the institutional conceptions about what ought to be developed in School Physical Education in the period.
\end{abstract}

Keywords: School Physical Education; Physical Education Trends; PESC/UFSM History

\footnotetext{
${ }^{\mathrm{I}}$ Instituto Federal Farroupilha - IFFar - Endereço: Rodovia RS 527, s/n, Distrito de São João do Barro Preto, Júlio de Castilhos, RS, CEP $98130-000$ - e-mail: juliano.rosa@iffarroupilha.edu.br

II Universidade Federal de Santa Maria - UFSM - e-mail: schmitzg@gmail.com

III Universidade Federal de Santa Maria - UFSM - e-mail: jlcunha11@yahoo.com.br

${ }^{\text {IV }}$ Universidade Federal de Santa Maria - UFSM - e-mail: ericsenqsilva@gmail.com
} 


\section{Resumen}

Este artículo resulta de una pesquisa de naturaleza histórica acerca del Centro de Educación Física e Deportes (CEFD) de la UFSM. El objetivo del estudio consistió en comprender los sentidos atribuidos por la Institución a la Educación Física Escolar, entre 1970 y 2004. Para tanto, la construcción metodológica involucró el entrecruzamiento de tres abordajes: entrevistas de Historia Oral Temática, revisión bibliográfica y revisión documental relativa a la formación profesional promovida por el CEFD. Las informaciones obtenidas en este proceso han permitido identificar la predominancia de perspectivas técnico-instrumentales y deportivas en las concepciones institucionales acerca de lo que debería ser desarrollado en la Educación Física Escolar, en el periodo.

Palabras clave: Educación Física Escolar; Tendencias de la Educación Física; Historia del CEFD/UFSM

\section{Introdução}

É relativamente recente o estabelecimento da trajetória institucional do Centro de Educação Física e Desportos (CEFD) da Universidade Federal de Santa Maria (UFSM). Denominado inicialmente de Centro de Educação Física (CEF), suas atividades tiveram início em 14 de maio de 1970, na esteira de um processo de reestruturação da UFSM, no qual suas faculdades e institutos foram substituídos por centros de formação (PROPLAN, 1981).

À época, vivia-se sob uma Ditadura Civil/Militar no comando do país, sendo que a estruturação e a funcionalidade da nova instituição foram significativamente viabilizadas por meio de articulações, consultoria e apoio financeiro dos militares, como nos lembram Mazo (1997) e Ustra (1969). Este último, encarregado de parecer especializado referente à estrutura e organização da futura Escola Superior de Educação Física da UFSM, mediante solicitação do reitor da universidade junto ao Comando da $3^{\mathrm{a}}$ DI do Exército Brasileiro.

É significativo observar que o surgimento do CEFD se deu no contexto incipiente da interiorização do ensino superior no país. A UFSM, fundada em 1960, foi a primeira universidade pública federal localizada fora de uma capital de estado no Brasil (UFSM, 2005). Um acontecimento que promoveu novas dinâmicas, fluxos e perspectivas para a sociedade a partir da formação promovida em sua espacialidade singular na oficiosidade do sistema de ensino regional.

De fato, o marco escolar é influenciador da realidade por meio dos particulares recortes culturais que estabelece (MAGALHÃES, 2004). Em função dessa peculiaridade é compreensível que o CEFD tenha impactado, desde sua criação, em aspectos orientadores das condutas humanas, estabelecendo determinados sentidos sobre eles em oposição a outros possíveis. Um potencial que, em última análise, representa fenômeno inerente a toda relação social institucionalizada no tempo (BERGER; LUCKMANN, 2002). 
De forma semelhante, a própria vinculação hierárquica do CEFD ao aparelho de Estado ${ }^{1}$ remete a esse potencial. Na condição de estrutura política, jurídica, normativa e coercitiva (ABBAGNANO, 2007), o Estado assume, entre suas funções, a organização de redes de ensino destinadas à formação dos cidadãos. Autorizadas e ou organizadas por essa instância, as instituições educativas, simplesmente por existirem, transformam informações em imposição organizacional no meio, pois essa é uma peculiaridade geral aos aparelhos sociais (MORIN, 2005). Ademais, uma condição que só é reforçada pela ciência como fonte fundamental de conhecimento na educação formal, dado o seu status destacado na explicação da realidade nos últimos quatrocentos anos (SANTOS, 1995).

Tal entendimento é, aqui, referencial que motiva e justifica a realização do estudo histórico da Instituição Educativa, e leva ao objetivo geral em torno do qual foi construído esse artigo, qual seja: compreender os sentidos atribuídos pelo CEFD à Educação Física Escolar, entre 1970 e 2004. Sentidos que, nesse caso, representam a construção de concepções que caracterizam e definem uma identidade para a Educação Física na escola.

O recorte temporal estabelecido abarca a graduação dos alunos mediante uma forma de licenciatura plena $^{2}$ descontinuada pela legislação brasileira a partir de 16/10/2005 (FORMA; WOLLINGER, 2010). Ao abordarmos tal dinâmica, a intenção é restabelecer aspectos de uma cultura escolar específica, histórica, integrante de um quadro maior que podemos chamar de cultura de movimento (BRACHT, 2005).

Para tanto, são discutidos dados representativos de um conjunto que originou a tese doutoral de Rosa (2017), ao passo que percorremos aspectos da constituição espacial da Instituição, dos projetos pedagógicos, da produção no ensino, na pesquisa e na extensão, entre outras questões relevantes para entendermos a formação promovida no CEFD. Uma iniciativa que pode, eventualmente, contribuir para se identificar, em escala regional, o que Betti (1991) referenciou como conceito de homem e de sociedade sob os quais todas as relações educativas são estabelecidas.

\section{Encaminhamento metodológico}

A metodologia utilizada na pesquisa envolveu quatro ações: abordagem documental, bibliográfica, entrevistas de História Oral Temática, e interpretação das informações com base nos sentidos de cada conteúdo e nas referências contextuais derivadas da 'sobreposição' destes.

\footnotetext{
${ }^{1}$ Aqui, noção sistêmica a partir da qual o Estado é concebido como estrutura de emancipação e regulação sociais, dispondo, para tanto, de outros aparelhos - militar, educacional, etc. - (MORIN, 2005).

${ }^{2}$ Equivalente ao bacharelado e a licenciatura em curso único. O título de 'Técnico Desportivo' - compatível à especialização -, exigia cursar mais duas disciplinas esportivas após a licenciatura (MAZO, 1997).
} 
Ao longo de 2015 foram consultados nove mil seiscentos e setenta e um documentos a respeito da organização acadêmico-institucional do CEFD, localizados no Arquivo Geral da UFSM e nas salas de arquivos na sede da Instituição ${ }^{3}$. Os registros foram fotografados e classificados em categorias conforme o conteúdo: Currículos, Catálogos, Ementários, Planos Estratégicos, Ofícios, Projetos, Solicitações, Listas de Teses e Dissertações, Listas de Disciplinas, Relatórios, e Trabalhos de Ensino, Pesquisa e Extensão.

Em 2016 foram realizadas as entrevistas seguindo-se o protocolo da História Oral Temática - por se abordar assunto específico relacionado à vida dos colaboradores (MEIHY; HOLANDA, 2015). Foram construídos documentos materiais de natureza histórica com a participação de cinco entrevistados escolhidos da seguinte forma: inserção institucional vinculada ao recorte temporal da pesquisa; a idade, já que os mais velhos costumam apresentar narrativas mais 'livres'; e a abrangência da atuação no contexto institucional.

A busca bibliográfica se deu, também, em 2016. Inicialmente, em meio virtual - Google Acadêmico - procurando possíveis obras não indexadas. Após, consulta às listas de referências nas obras encontradas e consulta ao sistema das bibliotecas da UFSM. Os descritores utilizados foram: 'CEFD', 'CEFD/UFSM' e 'Centro de Educação Física da Universidade Federal de Santa Maria'.

\section{CEFD: espacialidade, currículos e tendências formativas}

O CEFD estabeleceu sua sede no estádio universitário Tarso Dutra em maio de 1970, mediante uma adaptação das estruturas que, originalmente, não foram concebidas para o desenvolvimento de aulas (MAZO, 1997). Desta forma, constituía-se a primeira espacialidade institucional. Um complexo que, como toda edificação escolar, materializou traços das preocupações e dos valores relacionados a uma época (OLIVEIRA; GATTI JÚNIOR, 2002). Nesse caso, uma materialidade que remete, em um primeiro olhar, à simbologia esportiva na ideia da arena onde o ‘jogo’ é a centralidade dos sentidos.

Com o chamado 'Milagre Econômico', no Brasil, a situação estrutural da Instituição evoluiu consideravelmente. Em 1976, além do campo de futebol e das salas de aula convencionais, havia um conjunto de piscinas térmicas, ginásio poliesportivo, pistas e instalações para provas de atletismo, quadras polivalentes, quadras de areia, salas para judô, entre outras (MAZO, 1997). As instalações figuravam entre

\footnotetext{
${ }^{3}$ Dado o formato da publicação, apenas fração específica é relacionada nesse artigo.
} 
as mais completas do país, contribuindo para que o Centro alcançasse a condição de referência no campo da Educação Física nacional, na década de 1980 (UFSM, 2017).

De fato, a observação das estruturas é o olhar inicial daquele que chega. E como referência arquitetônica na paisagem traduz, em sua historicidade, características identitárias do Centro de Educação Física, visto que a dimensão objetiva de uma instituição cria especificações e níveis que repercutem nas relações por ela promovidas (WERLE, 2004). O mais evidente naquela progressão estrutural é, mais uma vez, a forte relação com o esporte em seu caráter formal.

Parte da explicação para essa ocorrência reside no fato de que o regime Ditatorial, estabelecido no país em 1964, dedicava especial atenção à Educação Física e ao esporte sob a perspectiva do desenvolvimento e da segurança nacional (CASTELLANI FILHO, 1994). Nesse contexto, temos, por exemplo, o primeiro decano do CEFD, o coronel Milo Darci Aita - personalidade intensamente ativa na criação do Centro; os primeiros professores do curso, com significativa experiência esportiva e influência militar em suas formações (MAZO, 1997); e o Decreto $n^{\circ}$ 69.450/71 que referenciava, entre outras questões, a educação física como atividade básica para se atingir as finalidades da educação nacional, apontando objetivos e referências para seu desenvolvimento.

Assim, o CEFD foi sendo organizado em estreito alinhamento à normatividade do período, consolidando o chamado 'Currículo Mínimo' da graduação por meio de relações de saber predominantemente práticas. Quatro dos cinco colaboradores do estudo confirmam esse entendimento ao apontarem, com pequenas variações discursivas, que "[...] as aulas eram práticas... Havia teoria, mas a vivência era bem importante" (JOAQUIM $\left.{ }^{4}, 2016\right)$. Aprendiam-se técnicas, conceitos, metodologias e noções diversas com acentuado nível de experimentação motora.

A maior abordagem teórica dos conteúdos ocorria nas disciplinas básicas, que apresentavam carga horária baixa em comparação com as 'Matérias Profissionalizantes'. Como exemplo, 'Estrutura e Funcionamento do Ensino de $2^{\circ}$ Grau', 'Psicologia da Educação' e 'Didática', juntas, apenas se aproximavam das duzentas e quarenta horas/aula dedicadas ao Atletismo, enquanto essa última representava parte das mil horas/aula, aproximadamente, destinadas às disciplinas técnicoprofissionalizantes (MAZO, 1997).

O ‘Relatório 1970’ (CEFD, 1970), por sua vez, traz reiteradas considerações sobre o ensino, ligando-o a ideia de "pôr acentuado trabalho prático" para que os alunos desenvolvessem habilidades

\footnotetext{
${ }^{4}$ Nomes fictícios.
} 
motoras, enquanto o 'Catálogo Geral' (UFSM, 1978), e o ementário (UFSM, 1980/81) apresentam repetidas indicações sobre "conhecer e executar" e "compreender e executar" fundamentos, técnicas ou ações técnico-táticas.

Em sentido semelhante, ainda na década de 1980, encontramos o 'Plano Estratégico' (CEFD, 1988/89) destacando, entre outras coisas, a importância da realização de eventos formativos que oportunizassem a "transmissão de conhecimentos" aos graduandos.

A ênfase nas práticas e na transmissão é indício de uma perspectiva instrumental nas relações de saber promovidas nos primeiros anos do curso, ou seja, relações nas quais o conhecimento é considerado objeto que pode ser utilizado ou repassado como uma ferramenta. Pode-se dizer, inclusive, que a legislação brasileira respaldava essa perspectiva, quando menos, com o Decreto $\mathrm{n}^{\circ} 69.450 / 71$ determinando a aptidão física como parâmetro para o planejamento, controle e avaliação da aprendizagem nas aulas de educação física.

Cabe destacar que, ao longo do século XX, a área, de um modo geral, foi pautada por um ensino que privilegiou o caráter técnico-instrumental ${ }^{5}$ do movimento humano, desconsiderando maiores relações entre as práticas e o contexto histórico, político e social dos indivíduos. A formação profissional se deu na “[...] perspectiva do saber fazer para ensinar” (DARIDO, 1995, p. 124).

$\mathrm{Na}$ Instituição, intimamente ligado a essa prática estava o conteúdo esportivo. Os cinco colaboradores do estudo referenciaram sua hegemonia na graduação. Segundo Manuel (2016), "no início, o esporte foi o ponto central do CEFD. Eu até diria assim: como o esporte era muito forte, foi meio negligenciada a parte pedagógica”. Uma referência aos limitados relacionamentos, no curso, entre o movimento e os diferentes aspectos concebíveis na formação humana.

O 'Relatório - Departamento MTD' (CEFD, 1979) destaca, inclusive, a importância da conscientização dos docentes do CEFD sobre "a missão de educadores", em vez de se limitarem à ação de treinadores esportivos. Nesse caso, para além da centralidade do esporte, a indicação é a do rendimento como perspectiva sob a qual o conteúdo era desenvolvido e avaliado. Natureza típica da manifestação esportiva formal.

No início daquela década os ementários indicam aproximadamente 32\% de disciplinas esportivas compondo a graduação, enquanto em 1981 eram aproximadamente 56\%, sem, no entanto, referenciarem todas as disciplinas do currículo ${ }^{6}$.

\footnotetext{
${ }^{5}$ Conhecimento para ação e ação em contextos restritos, utilitaristas e especializados.

${ }^{6}$ Como as chamadas 'matérias pedagógicas' - Psicologia da Educação, Didática, e Estrut. e Funcionamento do Ensino do $2^{\circ}$ grau -, desenvolvidas por professores do CE/UFSM (MAZO, 1997).
} 
Mais uma vez, o governo federal pareceu ter papel importante nessa tendência, já que promovia o esporte “[...] à razão de Estado [...]” (BETTI, 1991, p. 100). Tanto que a partir da Lei n 6.251/75 o CEFD passou a desenvolver os projetos: Desporto de Massa, Desporto de Alto Nível e Desporto Estudantil (MAZO, 1997). Os dois últimos objetivando a formação de atletas na comunidade.

Na década de 1980, porém, surgiam críticas sistemáticas ao caráter tecnicista e esportivista da Educação Física no País, especialmente com o desenvolvimento dos programas de mestrado - na área -, com o retorno de pesquisadores que estudaram fora do Brasil, e com as novas perspectivas no cenário sóciopolítico nacional (DARIDO, 2008).

Em tempos de abertura democrática, motivado pelas transformações no campo da Educação Física, e em atendimento à Resolução CFE ${ }^{\circ}$ 03/877 , foi elaborado, em 1990, novo projeto de curso, reformulando a graduação (CEFD, 1990). O documento, organizado por meio das chamadas Matérias de Cunho Técnico, Humanístico e Complementares, trouxe, entre outras mudanças, uma alteração na forma de abordar os conteúdos. Houve tendência das ementas priorizarem o "conhecimento e a compreensão", a "análise e a avaliação", e a interpretação dos fenômenos ligados ao movimento humano, observando a necessidade de aplicação dos conhecimentos na prática. Tais noções foram apresentadas recorrentemente na exposição de objetivos nas três categorias disciplinares apresentadas no projeto.

Essas informações vêm ao encontro do trabalho de Bitencourt (2006), que observou um progresso em relação ao currículo anterior, ao passo que incluía, na formação discente, conhecimentos sobre o homem e a sociedade associados a perspectivas filosóficas. Tanto que encontramos 'Antropologia do Movimento' e 'Filosofia e História da Ciência' entre as matérias a serem estudadas na graduação.

No entanto, as ementas permitiram identificar apenas duas disciplinas promovendo contextualizações históricas acerca do movimento humano, revelando o limite da previsão formal sobre o relacionamento dos conteúdos com um aspecto importante na constituição da cultura de movimento. Esse achado reforça a tese de um desenraizamento sociocultural daquele currículo ${ }^{8}$ (SOUZA; COUTO; MARIN, 2014).

Já as disciplinas dedicadas ao esporte continuaram com expressiva carga horária no currículo, totalizando 600 h/aula. O que representava, aproximadamente, 24\% do total da grade. Esse percentual era apenas parte da carga das disciplinas de Cunho Técnico, que na sua totalidade correspondiam a

\footnotetext{
${ }^{7}$ Fixava conteúdos mínimos e duração da graduação em Educação Física, prevendo ênfase democrática, crítica e reflexiva na formação.
}

${ }^{8}$ Distanciando-se, em parte, da Resolução CNE/CP n ${ }^{\circ} 1 / 2002$, que determinava uma formação contextualizada e interdisciplinar. 
aproximadamente $57 \%$ do volume de horas/aula do curso, enquanto as disciplinas de Cunho Humanístico aproximavam-se dos $38 \%$.

No que se refere ao número total de disciplinas esportivas, temos com o ‘Ementário’ (UFSM, 1994), e com o 'Catálogo 1996-97’ (UFSM, 1996/97), uma evolução de 46\% para 59\% no currículo, sendo este o último período referente ao qual encontramos ementas nos arquivos.

Ademais, atentando-se para os 'Trabalhos de Ensino, Pesquisa e Extensão' produzidos por professores e alunos no CEFD, entre 1974 e 2003, evidenciamos 45\% destes apenas nas áreas do esporte, da fisiologia, da biomecânica, e de medidas e avaliação em Educação Física - de mil trezentos e sessenta e dois resumos analisados em relatórios e registros de projetos localizados nos arquivos do CEFD.

Em sua totalidade, esses dados revelam aspectos gerais da construção de uma cultura escolar que levou o CEFD a ser considerado centro de excelência esportiva em 1998, pela Secretaria Nacional de Esportes do Ministério de Esporte e Turismo brasileiro9 (UFSM, 2005). Uma cultura sob influência das ciências exatas e naturais, como referenciou Mazo (1997) ao abordar a pós-graduação do CEFD ${ }^{10}$.

Tal perspectiva, diga-se, rendeu uma produção no mestrado e no doutorado centrada em áreas como Crescimento e Desenvolvimento Humano, Aprendizagem Motora, Fisiologia do Exercício, e-Medidas e Avaliação em Educação Física, conforme análise de quarenta e cinco teses (1995 - 2004), e duzentas e vinte e quatro dissertações $\left(1981\right.$ - 2004) produzidas na instituição ${ }^{11}$.

\section{Referências específicas à Educação Física Escolar}

Quatro das cinco narrativas identificaram o esporte como conteúdo destacado na compreensão estabelecida institucionalmente em relação ao que deveria constituir a Educação Física Escolar. Um posicionamento ilustrado pelo Parecer CEE n 32/79, da Comissão de Legislação e Normas do Conselho Estadual de Educação do Rio Grande do Sul (RIO GRANDE DO SUL, 1979). Consta no documento que o Departamento de Desportos Coletivos do CEFD solicitou à $8^{a}$ Delegacia de Educação a validação das práticas desportivas desenvolvidas por escolares entre seis e dezoito anos no 'Projeto Desporto de Alto Nível'. O objetivo era contribuir com a formação integral dos alunos, com a formação de equipes escolares

\footnotetext{
${ }^{9}$ Não encontramos documentos sobre as instalações físicas no período. Porém, sabemos que em 1982 havia o Laboratório de Pesquisa e Ensino do Movimento Humano (LAPEM) ligado à Fisiologia do Exercício, à Biomecânica e à Aprendizagem Motora (MAZO, 1997).

${ }^{10}$ Paradigmas ligados às Ciências Sociais e Humanas, especialmente com os professores alemães, visitantes, encontraram dificuldades em prosperar no mestrado do CEFD (MAZO, 1997).

${ }^{11}$ Não contabilizamos trabalhos da Especialização Permanente em Técnicas Desportivas. A produção estava misturada a de outros cursos na Biblioteca Central da UFSM. Sabemos, porém, que eram dezoito edições em 1992, e que a definição do esporte abordado a cada edição baseava-se, principalmente, nos mais desenvolvidos nas escolas (MAZO, 1997).
} 
e com o desenvolvimento técnico em nível competitivo nacional e internacional. Para tanto, o CEFD se comprometia a enviar notas e frequências discentes às escolas, bimestralmente.

De parecer contrário, o CEE esclareceu que a prática esportiva compunha a menor parte da formação escolar. A divergência derivou de interpretações diferentes do Decreto $n^{\circ} 69.450 / 71$. Uma probabilidade nas relações institucionais, já que as regulamentações do Estado operam em diferentes níveis, hierarquias e contextos de organização, tendendo a sofrer 'desvios'12 (MORIN, 2005).

Nesse período os ementários consultados ${ }^{13}$ indicam que 'Recreação/Hist./Org./Legislação da Educação Física II’ mencionava, em um tópico, o planejamento da recreação escolar. Antes, em 1970, de forma muito semelhante, também ‘Recreação I' e 'II', enquanto 'Rítmica I' e 'II', 'Voleibol II' e ‘Educação Moral e Cívica', abordavam, respectivamente, a adaptação de movimentos rítmicos, o voleibol moderno, e a orientação para trabalho, no meio escolar.

Com o currículo de 1990 as menções à escola aumentaram significativamente. Nove disciplinas abordavam questões como: problematização da Educação Física na educação brasileira, contextualização de teorias da aprendizagem nas práticas pedagógicas, e experiências educacionais no $1^{\circ}$ e $2^{\circ}$ graus, além de contemplarem preocupações da ordem de conhecer, compreender e interpretar aspectos ligados ao movimento humano - seguidos da aplicação prática dos saberes.

É possível afirmar que o Projeto Pedagógico de Curso (PPC) trouxe uma valorização da Educação Física Escolar, ao passo que se ocupou de questões relacionadas às finalidades, aos problemas e às formas de mediação das ações educacionais. A inclusão de perspectivas críticas em tal processo estava em conformidade com a própria Resolução CFE n 03/87.

No entanto, algumas questões necessitam ser pontuadas. A carga horária das disciplinas ligadas à Educação Física Escolar representava apenas $21 \%$ do total de horas/aula previstas no currículo ${ }^{14}$. Dado que sugere relativizarmos o avanço no PPC no que se refere à formação para o trabalho nas escolas, embora a pura análise quantitativa seja insuficiente para maiores conclusões.

Na mesma direção, Bitencourt (2006) indica que a especificidade da escola pouco figurou nas aulas dos professores à frente das disciplinas de caráter técnico, entre 2001 e 2004 - o que justifica a análise percentual -, mesmo que as bibliografias indicadas nos planos de ensino previssem essa possibilidade.

\footnotetext{
12 A noção definidora desses eventos chama-se ‘ecologia da ação' (MORIN, 2005).

${ }^{13}$ Novamente, não encontramos ementas das 'matérias pedagógicas'.

${ }^{14}$ Percentuais aproximados - Matérias Complementares não contabilizadas.
} 
Não foi possível identificar ementas e cargas horárias das disciplinas técnicas àquela altura. No entanto, com base no 'Catálogo 1996-97' (UFSM, 1996/97), podemos dizer que dezessete dos vinte e nove componentes curriculares, na ocasião, eram de caráter técnico, e que $27 \%$ do total abordavam a Educação Física no contexto escolar.

Parte daquelas disciplinas que tratavam das relações escolares apresentava a temática como um de seus tópicos, destinando-se, também, a abordar conteúdos extraescolares. Esse é o caso de 'História da Educação Física Brasileira' e 'Fundamentos da Educação Física II'. Esta última, tratando, por exemplo, do desporto de alto nível e do lazer. Por conta disso, os percentuais em questão, e, com isso, as ênfases, apresentam diferença ainda maior na composição efetiva do currículo.

No mestrado institucional também encontramos referência à escola. No projeto do curso, Fensterseifer (1978) relaciona a disciplina 'Currículo e Ensino da Educação Física' que abordava, em um de seus tópicos, os fundamentos da Educação Física e suas implicações em diferentes níveis de ensino; e 'Planejamento Educacional', que enfatizava, entre outras questões, relações de ensino e aprendizagem sob uma perspectiva Desenvolvimentista - na qual “[...] o movimento é o principal meio e fim da Educação Física [...]" (DARIDO, 2008, p. 4). As duas ainda figuravam no currículo do mestrado em 1997, mas em listagem simples, não permitindo comparação.

Por fim, o 'Plano de Ação' (CEFD, 1984) indica a intenção de ampliar a atuação institucional na educação básica por meio dos estágios discentes. Com isso, projetava-se "dinamizar” o trabalho nas séries iniciais do $1^{\circ}$ grau em Santa Maria. Porém, não há referências quanto à forma como isso seria realizado ${ }^{15}$.

Tal preocupação pode estar relacionada com os achados nos 'Trabalhos de Ensino, Pesquisa e Extensão' produzidos no CEFD. Apenas $6 \%$ abordaram questões ligadas à Educação Física Escolar, sendo $76 \%$ destes entre 1993 e 1999. As produções apresentaram enfoques variados, como gênero, valores humanos, avaliação, esportes e desenvolvimento de habilidades motoras em geral. Não indicando, desta forma, sentidos, volume ou linha diversa, consistente, na abordagem do campo escolar, diante dos referenciais hegemônicos até então verificados.

\section{Considerações finais}

As informações a respeito da formação desenvolvida no CEFD no período entre 1970 e 2004 permitiram identificar o estabelecimento de um curso com enfoque técnico em suas primeiras décadas. Até 1989, pelo menos, os dados sobre a espacialidade institucional e as relações educacionais nela construídas

${ }^{15}$ Com Canfield (1975) e com o conteúdo das entrevistas infere-se o desenvolvimento dos estágios com expressivo fundamento esportivo. 
evidenciam a articulação do ensino em torno do rendimento físico/desportivo/motor. A perspectiva fundamental residia no ensino da prática para a aprendizagem do ofício, contexto no qual a temática escolar foi pouco expressiva.

A partir de 1990, com o novo projeto curricular, ampliou-se a abordagem da Educação Física na escola, perspectivando a formação de perfis profissionais mais críticos. Previa-se a consideração de problemas, finalidades e formas de mediação das relações educacionais por meio do movimento. Contudo, a carga horária dessas disciplinas permaneceu inferior àquelas dedicadas ao esporte, e ao total de disciplinas de caráter técnico. Ainda, parte delas abordava tópicos não escolares, como o próprio desporto de alto nível.

Nesse contexto, permanecia um ensino estreitamente vinculado ao domínio técnico e esportivo, destacando-se de outras perspectivas educacionais que, independente da intencionalidade, resultaram acessórias na graduação. Os próprios estágios discentes estiveram significativamente atrelados a essa lógica, enquanto o currículo não previa a contextualização histórico-social dos saberes. Isso restringiu as possibilidades de vivência crítico-reflexiva dos conteúdos na formação, ainda que a orientação normativa do período apontasse o contrário.

Ao passo que ideias educacionais ligadas às Ciências Sociais e Humanas não alcançaram grande repercussão no programa de pós-graduação do CEFD, este pouco contribuiu para ampliar discussões na área da Educação Física Escolar. A temática foi pouco estudada e quando abordada envolveu perspectivas da ordem dos efeitos do treinamento, das características neuromotoras e dos tipos de sistema nervoso dos indivíduos diante da aprendizagem, reforçando a ideia da técnica e do alto rendimento no ambiente escolar.

É importante ter claro que o CEFD produziu vasta e, ao que tudo indica, excelente formação ao longo dos anos em áreas como Medidas e Avaliação em Educação Física, Aprendizagem Motora, Fisiologia do Exercício, Treinamento Desportivo e Biomecânica, mediada, em boa parte, pelo vínculo com o fenômeno esportivo. Contudo - e essa é uma limitação do artigo -, dada à incompletude documental a respeito da produção acadêmica no período, é possível que o panorama geral fosse sensivelmente diferente com os dados completos.

Por conta dessas características, os sentidos predominantes estabelecidos pelo CEFD em relação à Educação Física Escolar foram da ordem das competências técnico-instrumentais, fundadas na perspectiva esportiva. Concepções que sugeriam o ensino sobre o movimento humano em contextos de organização, controle e superação individual por meio do esforço físico. 
Serão necessários novos estudos para confirmar, ou não, a consolidação de tais concepções nas escolas sob influência do CEFD, de modo a compreendermos melhor a evolução da Educação Física Escolar até nossos dias.

\section{Referências}

ABBAGNANO, Nicola. Dicionário de Filosofia. São Paulo: Martins Fontes, 2007.

BERGER, Peter. L.; LUCKMANN, Thomas. A Construção Social da Realidade. Petrópolis: Vozes, 2002.

BETTI, Mauro. Educação Física e Sociedade. São Paulo: Editora Movimento, 1991.

BITENCOURT, Alex I. A Construção da Identidade do Curso de Educação Física no Contexto da Formação dos Professores. 2006. 59 f. Monografia (Especialização em Gestão Educacional). UFSM, Santa Maria, 2006.

BRACHT, Valter. Cultura Corporal, Cultura de Movimento ou Cultura Corporal de Movimento? In: SOZA JÚNIOR, M. Educação Física Escolar: teoria e política curricular, saberes escolares e proposta pedagógica. Recife: EDUPE, 2005. p. 97-106.

BRASIL. Decreto n. 69.450, de 1 de novembro de 1971. Regulamenta o artigo 22 da Lei no 4.024, de 20 de dezembro de 1961, e alínea c do artigo 40 da Lei 5.540, de 28 de novembro de 1968 e dá outras providências. Disponível em: http://www.planalto.gov.br/ccivil_03/decreto/d69450.htm. Acesso em: 01 jun. 2017.

BRASIL. Lei n. 6.251, de 8 de outubro de 1975. Institui normas gerais sobre desportos, e dá outras providências. Disponível em: http://www.planalto.gov.br/ccivil_03/leis/1970-1979/L6251. Acesso em: 01 jun. 2017.

BRASIL. Resolução CNE/CP n. 1, de 18 de Fevereiro de 2002. Institui Diretrizes Curriculares Nacionais para a Formação de Professores da Educação Básica, em nível superior, curso de licenciatura, de graduação plena. Disponível em: http://portal.mec.gov.br/seesp/arquivos/pdf/res1_2.pdf. Acesso em: 01 de jun. 2017.

BRASIL. Resolução n. 03, de 16 de junho de 1987. Fixa os mínimos de conteúdo e duração a serem observados nos cursos de graduação em Educação Física (Bacharelado e/ou Licenciatura Plena). Disponível em: http://crefrs.org.br/legislacao/pdf/resol_cfe_3_1987.pdf. Acesso em: 01 de jun. 2017.

CANFIELD, Jefferson T. Educação Física e Desporto Universitário: aplicação do Dec. 69.450/71 na UFSM. Santa Maria: Imprensa Universitária - UFSM, 1975.

CASTELLANI FILHO, Lino. Educação Física no Brasil: a história que não se conta. Campinas: Papirus, 1994.

CEFD. Plano de Ação. Santa Maria: Arq. CEFD, 1984.

CEFD. Plano Estratégico. Santa Maria: Arq. CEFD, 1988/89.

CEFD. Projeto de Curso/Currículo. Santa Maria: Arq. CEFD, 1990. 
CEFD. Relatório 1970. Santa Maria: Arq. CEFD, 1970.

CEFD. Relatório - Departamento MTD. Santa Maria: Arq. CEFD, 1979.

DARIDO, Suraya C. Educação Física na Escola: questões e reflexões. Rio de Janeiro: Guanabara Koogan, 2008.

DARIDO, Suraya C. Teoria, prática e reflexão na formação profissional em Educação Física. Revista Motriz, v. 1, n. 2, p. 124-128, dez. 1995.

FENSTERSEIFER, Haimo. H. Projeto do Curso de Pós-Graduação em Nível de Mestrado. Santa Maria: Arq. CEFD, 1978.

FORMA, Gabriela M.; WOLLINGER, Paulo R. Nota Técnica Nº03/2010 - CGOC/DESUP/SESu/MEC. Disponível em: http://www.confef.org.br/confef/comunicacao/revistaedf/3903. Acesso em: 12 jan. 2020.

JOAQUIM. Entrevista concedida ao autor. 2016.

MAGALHÃES, Justino P. Tecendo Nexos: história das instituições educativas. Bragança Paulista: Editora Universitária São Francisco, 2004.

MANUEL. Entrevista concedida ao autor. 2016.

MAZO, Janice. A História do Centro de Educação Física e Desportos da Universidade Federal de Santa Maria. Santa Maria: UFSM, 1997.

MEIHY, José C. S. B.; HOLANDA, Fabíola. História Oral: como fazer, como pensar. 2. ed. São Paulo: Contexto, 2015.

MORIN, Edgar. O Método 1: A Natureza da Natureza. 2. ed. Porto Alegre: Sulina, 2005.

OLIVEIRA, Lúcia H. M. M.; GATTI JÚNIOR, Décio. História das Instituições Educativas: um novo olhar historiográfico. Cadernos de História da Educação, v. 1, n. 1, jan./dez. 2002.

PROPLAN. Projeto nº 16/81. Cobertura de duas quadras esportivas. Santa Maria: Arq. CEFD, 1981.

RIO GRANDE DO SUL. Conselho Estadual de Educação. Parecer n. 32, de 19 jan. de 1979. Sobre solicitação CEFD/Projeto Desporto de Alto Nível. 8ª D.E.: Arq. CEFD, 1979.

ROSA, Juliano M. O CEFD/UFSM na Atribuição de Sentidos à Educação Física Escolar entre 1970 e 2004. 2017. 262 f. Tese (Doutorado em Educação). UFSM, Santa Maria, 2017.

SANTOS, Boaventura S. Um discurso sobre as ciências. 7. ed. Porto: Afrontamento, 1995.

SOUZA, Maristela S.; COUTO, Maíra L.; MARIN, Elizara C. A Relação entre as Ciências Sociais e as Ciências Naturais na Formação em Educação Física do CEFD-UFSM. Revista Pensar a Prática, v. 17, n. 1, p. 175-190, jan./mar. 2014.

UNIVERSIDADE FEDERAL DE SANTA MARIA. Catálogo 1996-97. Santa Maria: UFSM, 1996/97.

UNIVERSIDADE FEDERAL DE SANTA MARIA. Catálogo 1980/81: ementário. Santa Maria: UFSM, 1980/81. 
UNIVERSIDADE FEDERAL DE SANTA MARIA. Catálogo Geral 1978. Santa Maria: UFSM, 1978.

UNIVERSIDADE FEDERAL DE SANTA MARIA. Ementário. Santa Maria: UFSM, Arq. CEFD, 1994.

UNIVERSIDADE FEDERAL DE SANTA MARIA. Histórico. Santa Maria: UFSM, 2017. Disponível em: https://www.ufsm.br/cursos/graduacao/santa-maria/educacao-fisica/historico/. Acesso em: 22 Jun. 2017.

UNIVERSIDADE FEDERAL DE SANTA MARIA. Projeto Pedagógico de Curso (2005). Santa Maria, UFSM, 2005. Disponível em: http://coral.ufsm.br/edfisica/images/Ducmentos/PPC-BEL.pdf. Acesso em: 10 fev. 2017.

USTRA, Renato B. Projeto Escola Superior de Educação Física. Santa Maria: Arq. CEFD, 1969.

WERLE, Flávia O. C. História das Instituições Escolares: responsabilidade do gestor escolar. Cadernos de História da Educação, n. 3, p. 109-119, jan./dez. 2004.

\section{Como citar este artigo}

ROSA, J. M.; SCHMITZ FILHO, A. G.; CUNHA, J. L.; SILVA, E. Q. O CEFD na atribuição de sentidos junto à educação física escolar (1970 - 2004). Revista Kinesis, Santa Maria, Dossiê CEFD 50 anos, p.01-14, 2020.

* O presente trabalho não contou com apoio financeiro de nenhuma natureza para sua realização. 